\title{
A CLINICAL AND DEMOGRAPHIC STUDY OF SINGLE LESIONS IN LEPROSY
}

\author{
S. Ravindra Nath ${ }^{1}$ \\ ${ }^{1}$ Assistant Professor, Department of Dermatology, MGM/KMC Hospital, Warangal.
}

ABSTRACT

Leprosy is chronic granulomatous disease caused by M. Leprae, an intracellular obligate organism.

\section{AIM}

The aim of the study was to determine the incidence, clinical characteristics and mode of presentation of various clinical types of leprosy in single lesions in patients attending MGM Hospital, Warangal, over a period of 18 months.

\section{METHODS}

A total of 40 patients were examined. Single lesions in leprosy were classified as indeterminate, BT and TT type. Their clinical characters were recorded and analysed.

\section{RESULTS}

There were 11 females and 29 males. Male to female ratio 2.63:1. Common age affected was 11-50 years. The percentage single lesions among total leprosy patients was $12.5 \%$. There were 7 cases of indeterminate type, 27 cases of BT type of leprosy and 6 cases of tuburculoid type of leprosy.

\section{CONCLUSION}

Incidence of single leprosy lesions was $12.5 \%$ of total leprosy cases with male predominance. Common age affected was $20-30$ years. Hypopigmented patch was the most common complaint. Clinically borderline tuberculoid type is the most common variety. Posterior aspect of forearm was the commonest site. Indeterminate lesions were common in children.

\section{KEYWORDS}

Leprosy, Single Lesion, Hypopigmented Patch, Sensory Changes, Hypoesthesia, Anaesthesia, Indeterminate, Borderline Tuberculoid, Tuberculoid.

HOW TO CITE THIS ARTICLE: Nath SR. A clinical and demographic study of single lesions in leprosy. J. Evolution Med. Dent. Sci. 2016;5(13):526-530, DOI: 10.14260/jemds/2016/121

\section{INTRODUCTION}

Leprosy is a chronic granulomatous infection caused by obligate intracellular organism M. Leprae. ${ }^{1}$ infectious in some cases and affecting the peripheral nervous system, the skin and certain other tissues. ${ }^{2}$ Although prevalence has decreased, the incidence remains relatively static. ${ }^{3}$ Leprosy has been known and recorded throughout history, yet the disease remains an enigma. M. Leprosy presents an unparalleled challenge to the bacteriologist, the pathologist, the epidemiologist, the pharmacologist and practitioner of medicine. ${ }^{4}$ No other disease is as widespread and devastating in its effect as leprosy.

Single lesions are common in leprosy and are seen in wide variety of clinical leprosy. They may account for 15 to $86 \%$ of new cases. ${ }^{5}$ Single lesions may reflect the integrity of host immunity to the disease effectively preventing bacillary multiplication and these are commonly seen in TT, BT and indeterminate leprosy as well.

Financial or Other, Competing Interest: None.

Submission 13-01-2016, Peer Review 25-01-2016,

Acceptance 29-01-2016, Published 12-02-2016.

Corresponding Author:

Dr. S. Ravindra Nath,

House No. 11-24-57, Road No. 3,

M. V. Colony, Desaipet Road, Warangal,

Telangana State.

E-mail: drsravindranath009@gmail.com

DOI: $10.14260 /$ jemds $/ 2016 / 121$
There is consistent dearth of literature as to the single lesions in leprosy. Therefore, it was thought worthwhile to study single lesions in leprosy from a standpoint of their incidence, clinical type, morphological variations and site of occurrence on human body.

\section{METHODS}

The study was conducted in Dermatology Department of Mahatma Gandhi Memorial Hospital, Warangal, over a period of 18 months and is approved by local research ethical committee.

For all cases a detailed clinical history with regard to age, gender, occupation and duration of disease was recorded followed by thorough clinical examination.

Children below 5 years, patients on antileprotic treatment, pregnant women were excluded. Patients on corticosteroid and immunosuppressive therapy were also excluded. In all cases routine haematological and other laboratory investigations were done. Chest $\mathrm{x}$-rays were taken in all cases. HIV tests were not done.

Clinical aspects of Ridley and Jopling classification were used for diagnosis. The term maculo-anaesthetic leprosy pertaining to earlier Indian classification of Leprosy (1955) was not considered because maculo-anaesthetic leprosy was merged with tuberculoid type in the consensus classification of Indian Association of Leprologists (1981). One to three hypopigmented macules from 1 to $5 \mathrm{~cm}$ in size with sensory changes and with \pm nerve thickening were diagnosed as indeterminate leprosy. 
Macular lesions or plaques 1 to 3 in number with welldefined margins, dry, rough, irregular surface associated with anaesthesia and thickened nerves were labelled as tuberculoid leprosy.

Hypopigmented or erythematous macules or plaques with well-defined margin in one part to ill-defined margins in another part with altered sensation, reduced hair growth, varying from 3 to 10 in number were diagnosed as borderline tuberculoid leprosy. Single lesions in leprosy will have to be differentiated from the following disorders.

\section{Differential diagnosis of Macular Lesions Pityriasis versicolor}

Whitish to brown erythematous macules present on upper back, chest and neck. Fine brawny scaling and finding of Malassezia furfur in scales confirm diagnosis.

\section{Pityriasis Alba}

Circular to oval hypopigmented macules presenting with furfuraceous scaling. Commonly seen in children and disappear spontaneously. Sensation is normal.

\section{Vitiligo}

Depigmented macules are seen with normal sensations. Usually have convex, well-defined outer border. There are no thickened nerves. Histamine test is normal.

\section{Post Kala Azar Dermal Leishmaniasis}

Hypopigmented macules with or without erythema at margins, appearing on upper trunk limbs, limbs and face are the earliest findings. May be mistaken for macular leprosy of borderline type or lepromatous leprosy. No sensory changes. Leishman-Donovan bodies are present in skin biopsy.

\section{Morphea}

A white macule which may be slightly raised in parts, the edges often purple, hair growth and sweating are lost in the lesion. Impaired sensation may be mistaken for tuberculoid leprosy. Absence of regional nerve enlargement helps to differentiate. Histology is characteristic with atrophic epidermis and hyalinization of collagen.

\section{Differential Diagnosis of Infiltrated Lesions within Raised Margins}

Follicular mucinosis: Skin coloured or erythematous plaques favouring scalp, face, neck and shoulders. Mistaken for lepromatous leprosy. Histology with degenerating hair follicles with deposits of mucin is characteristic.

Granuloma Annulare: Mainly affects children and young adults and may resemble tuberculoid or borderline leprosy. Cardinal signs of leprosy are absent. Histology is characteristic with histiocytes arranged in palisade around central necrobiosis.

Syphilis: Annular lesions of syphilis may be mistaken for leprosy. Involvement of palms and soles, generalized lymphadenopathy, history of genital sore and positive serology (TPHA or VDRL) and response to penicillin will help to differentiate.

Lupus erythematosus: May be mistaken for borderline leprosy on face. There is a typical lesion with erythema, atrophy, follicular plugging and adherent scales. The histology is characteristic.

Lupus Vulgaris: Commences as papule which later becomes a plaque, yellow red in colour and irregular in shape.
When glass slide is pressed on it, papules appear as brown "Apple jelly" spots. Histological differentiation from TT is normal appearance of cutaneous nerves and by presence of caseation.

\section{RESULTS}

The present study included 40 patients with single leprosy lesions among a total of 360 leprosy patients accounting for $12.5 \%$ of total leprosy cases.

Among these 32 patients presented with hypopigmented patches, 4 patients with pale brown macules and 4 patients with plaques. Two of these patients had thickened superficial nerves supplying the lesions. Incidentally, both these patients had tuberculoid type leprosy clinically (Table 1).

In the present study, there were 11 females and 29 males. The common age group affected were between 11 and 50 years. The youngest patient was 10 years old girl and the oldest patient was 55 years old male. There were no patients above 60 years of age (Table 2 ).

In the present study of single lesions various clinical types were noted (Table 3). Indeterminate type with hypopigmented macule and well-defined edges associated with slight sensory loss accounted for 7 cases (17.5\%). Borderline tuberculoid with well-defined edges, dry surface and moderate sensory loss accounted for 27 cases (67.5\%). Tuberculoid type with clearly defined edges, dry surface, hair loss and with complete loss of sensation accounted for 6 cases $(15 \%)$. Four of these patients presented as plaques. Duration of illness varied from months to years from the time of onset to time of examination (Table 4).

The longest duration was 6 years and shortest duration was 2 months ( 7 cases). The lesions were asymptomatic in the majority and hypopigmented patch with sensory changes was the major complaint. Hypopigmented patch was complained by 23 patients $(57 \%)$, whereas 17 patients complained of hypopigmented patch associated with anaesthesia/ paraesthesia. Majority of indeterminate type cases complained of hypopigmented patch only, while majority of tuberculoid type complained of hypopigmented patch with anaesthesia.

\section{Past History}

Two patients gave history of suffering from similar lesson in the past. One patient reported single lesion which regressed following dapsone monotherapy followed by onset of the present single lesion in the vicinity of the previous lesion.

\section{Family History}

Borderline lepromatous leprosy was recorded in the husband of one female patient. Family history was not traceable in remaining cases.

\section{Socioeconomic Status}

In the present study of single lesions, majority of the patients hailed from lower middle class family.

\section{Anatomical Distribution}

Posterior part of the forearm is the (Figure 1) commonest site involved in all clinical types comprising 5 females and 12 females accounting for a total of 17 cases (42.5\%). Anterior leg is the next commonest (Figure 2) site in frequency with 5 cases (12.5\%) (All males) and is followed by posterior aspect of thigh (Figure 3) with 3 cases (All females) and posterior aspect of leg and wrist (Figure 4) 3 cases (7.5\%) each. Anterior aspect 
of thigh and neck come next with 2 cases (5\%) each. Face, trunk, dorsum of foot, anterior and posterior upper arm involved in one case each.

\section{Clinical Characteristics Margins}

In the present study, lesions are well defined in 1 male and 1 female in indeterminate leprosy. In borderline tuberculoid cases margins are well defined in 20 cases (15 males and 5 females). Among tuberculoid type of cases, the margins were raised in 4 cases (All males) and well defined in all cases.

\section{Sensory Changes}

In indeterminate lesions paraesthesia was present in 6 patients ( 3 males and 3 females) and hypoesthesia in one male. In borderline tuberculoid cases, hypoesthesia was present in all patients. Tuberculoid lesions were anaesthetic in all patients.

\section{Hair Growth}

Partial hair loss was present in 16 cases $(11$ males and 5 females) in borderline tuberculoid type. In tuberculoid type, complete hair loss is present in 4 patients (All males).

\section{Associated Conditions}

In the present study of single lesions other diseases were found to be associated with some cases. The association is purely coincidental.

\section{Laboratory Investigations}

Routine investigations were done in all patients. Haematological findings were within normal limits. Chest Xrays revealed cervical rib in one case.

\section{DISCUSSION}

In the present study, the percentage of single leprosy lesions among the total leprosy patients was found to be $12.5 \%$. JM Ponnighaus reported that single sessions accounted for 15 to $86 \%$ of new cases. ${ }^{5}$ Chaturvedi, in his study survey in Malwani Suburbs of Bombay, reported that single leprosy lesions accounted for $57.45 \%$ of the total leprosy cases. ${ }^{6}$ The low incidence of single leprosy lesions in the present study compared to other studies is probably because of the fact that single leprosy lesions are less prevalent in these parts of the state.

In the present study, no age and sex was found to be immune to single lesion in leprosy as the youngest patients was 8 years old girl and the oldest patients was 55 years old woman. In the present study, nearly $78 \%$ patients were below 30 years of age with a peak in the third decade, which indicates that single hypopigmented lesions are predominantly seen in adolescent age group. This observation is in agreement with study of other workers. ${ }^{7}$ Cochrane. ${ }^{4}$ notes that age at onset varies in different countries and in different areas within the same country.

The sex incidence of single lesions varied in different studies. In most prevalence studies males are affected rather more commonly than females. ${ }^{8}$ In this study male-to-female ratio was found to be 2.63:1 showing a male predominance.

The main factor causing the difference in sex prevalence has probably more opportunity among the males for contact with disease. Predominance of males over the age of 20 years was observed by Cochrane and Davey. ${ }^{9}$ Chacko et al. ${ }^{10}$ In the present study, most patients reported negative family history except in one female patient whose husband was suffering from borderline lepromatous leprosy. Hence, no comment can be made taking into consideration of the small size of the study.

Socioeconomic status: In the present study most of the patients hailed from lower middle class families living in overcrowded conditions with poor sanitation. It is well known that overcrowding promotes the spread of the disease irrespective of the mode of transmission.11,12 though this is disputed. ${ }^{13,14}$ Chaturvedi made similar observations. ${ }^{6}$

The duration of illness before reporting at the outpatient clinic varied from a few months to few years. In this study most of the cases have reported 1 year after the onset of the illness and nearly $20 \%$ reported 2 months after the onset of the illness. The early reporting to the hospital may be due to anxiety caused by the hypopigment lesion and late reporting may be due to hoping of spontaneous regression of the lesion. The fear of leprosy might have prompted them to seek medical attention at the earliest possible.

Though majority of patients complained of pain, weakness, dragging sensation and numbness of the limbs bearing the lesion, the most important complaint was an hypopigmented patch with altered sensation. The hypopigmentation of the lesion varied from wheat colour to light brown macule to wheat coloured plaques. The sensory changes varied from altered sensation to moderate loss of sensation to total loss of sensation. In the literature also, it was mentioned that single leprosy lesion presents clinically as hypopigmented macule with altered sensation. ${ }^{2,8}$ The studies of Chaturvedi. ${ }^{6}$ revealed similar findings.

In this study different clinical types of leprosy are observed. The term maculo-anaesthetic leprosy was not used, as it is rather confusing and controversial. W.H. Jopling opined that in maculo-anaesthetic group skin lesions are described as macular with well-defined edges and definite anaesthesia, absent bacilli in smears and leprominine reaction, which is moderately or strongly positive. These would include both BT and TT. ${ }^{2}$ Leiker..$^{15}$ calls it as low resistant tuberculoid leprosy. Maculo-anaesthetic leprosy was said to be separate category because of flat lesions in contrast to raised lesions of tuberculoid type leprosy. ${ }^{16}$ In consensus classification of Indian Association of Leprologists (IAL). (1981) maculoanaesthetic leprosy was merged with tuberculoid type and 5 group classification was agreed upon. ${ }^{17}$

Majority of the cases belonged to borderline tuberculoid group (67.5\%). This is most commonly seen in twenty to thirty years age group. Next commonly seen is the indeterminate type, which was observed in $17.5 \%$ of patients. Tuberculoid type of leprosy accounted for $15 \%$ of cases. All the patients in the tuberculoid group were males. In literature it was stated that borderline leprosy, especially borderline tuberculoid type, is commonest sites type of leprosy seen.2,18

The morphological features of single leprosy lesions observed in this study were variable in nature. Hypopigmented lesions with well-defined margins were noted in $70 \%$ of patients. These include majority of borderline tuberculoid and all tuberculoid patients.

Hypopigmented macules with ill-defined margins were seen in patients with indeterminate type of leprosy. Diminished hair growth on the lesion was observed in $59.27 \%$ of patients in borderline tuberculoid group. Patients with tuberculoid type lesions showed total loss of hair in $80 \%$ cases. Diminished hair growth was not a feature in indeterminate 
group. Hypoesthesia was the commonest sensory change, reported in $70 \%$ of patients in present study and nearly all of these patients had borderline tuberculoid lesions. Anaesthesia or total loss of sensation was reported only in $80 \%$ of tuberculoid type patients. Paraesthesia or altered sensation was observed in nearly $88 \%$ of patients with indeterminate lesions. These findings are in agreement with the observations of earlier workers. ${ }^{2,8}$

The commonest site of single lesion in the present study was posterior part of the forearm (42.5\%) followed by anterior aspect of leg (12.5\%), followed by posterior aspect of leg (7.5\%). One case each was noted on the anterior and posterior aspect of upper arm, rather an infrequent site of the lesion in the present study. Only one lesion each were noted on trunk, face and back. Cochrane and Davey. ${ }^{9}$ noted that limbs are the commonest sited for early lesion. JM Ponnighaus. ${ }^{19}$ et al. reported a striking excess of single lesions on the face and back of the arm compared to extent of skin surface area in these sites and a paucity of single lesions on legs regardless of age. Doull. ${ }^{11}$ et al. found an excess of lesions on extremities and opined that the lesion distribution might be an indication of skin entry. Machin has argued that in children the distribution of single leprosy lesions are essentially random, suggesting a systemic distribution of infection. Chaturvedi. ${ }^{6}$ reports that commonest sites are arm, thighs and buttocks. These are the anatomical sites that receive maximum trauma, friction and inflammation and these sites have more skin to skin contact. However, there is variation among sites in different age groups and in different regions. No explanation can be offered at the moment for these regional differences.

Probably the distribution of lesions does not suggest a pattern reflecting entry by Myco. Leprae nor does it suggest an association with anatomical distribution of the nervous or vascular system. It is argued that the distribution reflects the influence of some local environmental or behavioural factors of which an important factor could be clothing and sleeping habits if biting insects were involved in the transmission of $\mathrm{M}$. Leprae or if sun exposure is implicated in predisposition to the infection.

In our present study, ocular and neurological complications are not seen. Majority of the patients with single leprosy lesion are of borderline tuberculoid or tuberculoid type. Probably their higher immunological competence might have restricted the infection to single area in the body making such complications rare.

In the present study some associated conditions like renal calculi, cervical rib, pellagra, verruca vulgaris were present in one patient each and pityriasis versicolor and caries of teeth were observed in two patients each. The association of above conditions is probably coincidental and no significance need to be attached to them.

Haematological and serological: In this study leucocytosis was observed in $25 \%$ of the patients. Eosinophilia was observed in 3 patients. Haemoglobin and ESR were normal in all the patients. In earlier studies, abnormalities in routine haematological investigations were reported in single leprosy lesions. Defective platelet function, impairment in platelet adhesiveness and aggregation to collagen..$^{20}$ and raised levels of immunoglobulins. ${ }^{21}$ have been reported in literature. (These investigations were not studied due to lack of facilities available in this institute). Chest X-rays were normal in all cases except one patient whose radiograph revealed a cervical rib on the right side.

\section{CONCLUSION}

Single lesions in leprosy are commonly seen in TT, BT and indeterminate type of leprosy, most commonly among BT type. Physician and dermatologist have to carefully evaluate single lesions, because prompt diagnosis and therapy of single lesions in leprosy will contribute more meaningful steps towards the global eradication of leprosy.

\begin{tabular}{|c|c|}
\hline Number of Skin Lesions & \\
\hline Single & 40 \\
\hline Multiple & Nil \\
\hline Unknown & Nil \\
\hline Pattern of skin lesion & 32 \\
\hline Hypopigmented & 4 \\
\hline Pale brown macules & 4 \\
\hline Plaques & 2 \\
\hline Superficial nerves thickened & 38 \\
\hline Not thickened & Tables 1: Clinical Manifestations \\
\hline
\end{tabular}

\begin{tabular}{|c|c|c|c|c|}
\hline & & Sex & Fotal & Female \\
\hline $\begin{array}{c}\text { Age in } \\
\text { Years }\end{array}$ & Male & $\begin{array}{c}\text { No. of } \\
\text { Cases }\end{array}$ & \% \\
\hline $0-10$ & 1 & 1 & 2 & $5 \%$ \\
\hline $11-20$ & 7 & 2 & 9 & $22.5 \%$ \\
\hline $21-30$ & 17 & 3 & 20 & $50 \%$ \\
\hline $31-40$ & 2 & 0 & 2 & $5 \%$ \\
\hline $41-50$ & 2 & 4 & 6 & $15 \%$ \\
\hline $51-60$ & 0 & 1 & 1 & $2.5 \%$ \\
\hline $61-70$ & 0 & 0 & 0 & 0 \\
\hline \multicolumn{7}{|c|}{ Table 2: Age and Sex Distribution } \\
\hline
\end{tabular}

\begin{tabular}{|c|c|c|c|c|}
\hline Classification & Male & Female & $\begin{array}{c}\text { Total } \\
\text { no. of } \\
\text { Cases }\end{array}$ & $\%$ \\
\hline Indeterminate & & & & \\
\hline Type & 4 & 3 & 7 & $\begin{array}{c}17.5 \\
\%\end{array}$ \\
\hline Borderline- & & & & \\
\hline Tuberculoid type & 19 & 8 & 27 & $\begin{array}{c}69.5 \\
\%\end{array}$ \\
\hline Tuberculoid type & 6 & 0 & 6 & $15 \%$ \\
\hline
\end{tabular}

Table 3: Clinical Types

\begin{tabular}{|c|c|c|c|c|c|c|}
\hline \multirow{3}{*}{$\begin{array}{c}\text { Clinical } \\
\text { Types }\end{array}$} & & & & Duration & \multirow[b]{2}{*}{ In Years } & \multirow{3}{*}{$\begin{array}{c}\text { Total } \\
\text { Percentage } \\
\end{array}$} \\
\hline & \multicolumn{3}{|c|}{ In Months } & & & \\
\hline & $0-3$ & $4-6 \quad 7-9$ & $10-12$ & & $1-3 \quad 4-6$ & \\
\hline Indeter & 4 & -1 & 1 & & $1-$ & $17.5 \%$ \\
\hline BT & 4 & 5 & 12 & & 3 & $67.5 \%$ \\
\hline \multirow[t]{2}{*}{ TT } & - & 2 & 3 & & - & $15 \%$ \\
\hline & 8 & 3 & 16 & & 4 & \\
\hline \multicolumn{7}{|c|}{ Table 4: Duration of Illness } \\
\hline
\end{tabular}




\section{REFERENCES}

1. Lockwood D. Leprosy. Clin Evid 2006;1079-87.

2. Jopling WH and McDougall AC. Handbook of Leprosy. 2011, pp. 1.

3. Global leprosy situation, 2012. Wkly Epidemiol Rec 2012;87:317-28.

4. Chochrane RG. History of leprosy and its spread throughout the world: in leprosy in theory and practice pp 1-6: 1959.

5. Ponnighaus JM. Diagnosis and management of single lesions in Leprosy. Lepr Rev 1996;67:89-94.

6. Chaturvedi. Immunogenic subunit of the ICRC antileprosy vaccine. International Journal of Leprosy 1988; Vol 56:4.

7. Pramod Nigam K, Uttera Sehgal, et al. "Age of onset of leprosy." Indian Journal of Dermatology and Venereology: 1990;56, pp 213:215.

8. Anthony Bryceson and Roy E Pfaltzgraff. Leprosy. Churchill Livingstone, 3rd edition; 1990.

9. Badger LF. Epidemiology. In: Leprosy in theory and practice, 2nd Editors: Cochrane RG and Davey TF, John Wright, Bristol, 1964; pp 76-77.

10. Chacko, et al. The significance of nasal mucosa in indeterminate, tuberculoid and borderline leprosy: Leprosy India 1979;51(1): pp 8-22.

11. Doull JA, Rodriguez JN, Guinto RS, et al. A field survey of leprosy in Cebu. International Journal of Leprosy 1936;4: pp 141-170.

12. Marshall JT, Amar DS, Ramesh HC. "Prevalence of leprosy among slum dwellers.” Leprosy India 1981;53: pp 70-82.
13. Ali PM. An epidemiological leprosy survey in Chengalpattu district of Madras State. "Leprosy India” 1963;35: pp 175189.

14. Irgens LM. Epidemiological aspects and implications of the disappearance of Leprosy from Norway; some factors contributing to decline. Leprosy Review 1981;52: Suppl 1:pp 147-165.

15. Leiker DL. Low resistant tuberculoid leprosy: International Journal of Leprosy 1964;32: pp 359-367 cited by WH Jopling.

16. Dharmendra. The International Classification: In Dharmendra (Edit) Leprosy: Vol. 1 Kothari medical publishing house 1978; pp 258-62.

17. Indian Association of Lephrologists approved classification: Lepr India 1982;54: pp 22-32.

18. Vijaykumar, Baruah MC and Garg BR. A study of clinicohistopathological correlation of leprosy in children. Indian Journal of Leprosy. Vol. 61, No. 1: 1989; pp 68-71.

19. Ponnighaus JM, Fine PE, Maine N, et al. The Lepra Evaluation Project: an epidemiological study of Leprosy in Northern Malawi: I Methods: Leprosy review 1987; 58: pp 359-75.

20. Gupta M, Bhargava M, et al. Platelet function in leprosy. International Journal of Leprosy Vol. 43: No. 4, pp 327-332.

21. Saha K, Dutta RN and Dasgupta A. Immunologic aspects of leprosy with special reference to study of IgE. International Journal of Leprosy. 1975; Vol. 43, No. 4: pp 314-319. 